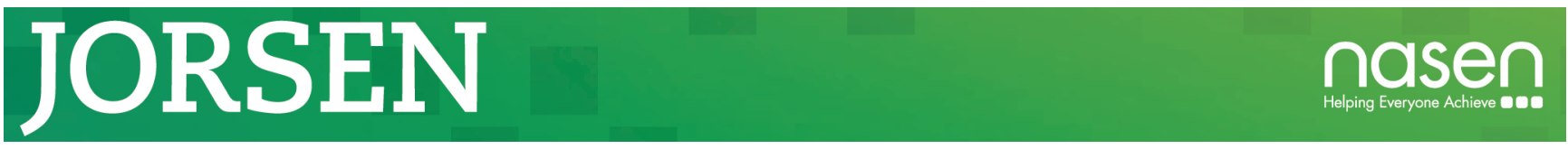

Journal of Research in Special Educational Needs • Volume 16 • Number s1 • 2016 285-289 doi: $10.1111 / 1471-3802.12290$

\title{
BRINGING STREET ART TO SCHOOL: OPEN TO INCLUDE
}

\author{
Graça Duarte Santos and Elisabete Varandas \\ Universidade de Évora
}

Palavras-chave: Inclusion, art, special educational needs, development and learning, challenging behaviour.

\begin{abstract}
Inclusive Education values differences by reducing barriers to learning and promoting active participation and positive interactions between all members of school community. Nowadays, school faces numerous children/adolescents who for several reasons have developed challenging behaviours and high risk of dropping out school. They come often from socio-cultural-economic minority groups and have sometimes a repeated course of academic failure. Art has had the ability to bring together the interests of all, even of the most unsuitable. In this paper, the authors present an intervention through street art/graffiti done in a secondary school, with a ninth grade class covered by PIEF Programme. The project aimed to understand if the integration of graffiti art in educational process had impact on challenging behaviour. The study, with a qualitative methodology, shows contributions of artistic experience as an asset to educational development of students with challenging behaviours contributing to a better school and inclusion.
\end{abstract}

\section{Introduction}

During centuries, art was conceptualised as the creation of noticeable expressive forms of human feeling, the realisation through the 'beauty' of an unattainable human dimension by conceptual language: the feeling (Langer in Hughes, 2009). In fact all artists and many psychologists refer that Art is a powerful way to externalise feelings, emotions and transform the inner and outer world. Rogers (1997) stated that all human beings have innate creative abilities that can be implemented through art. This was a basic element in the creation and expansion of the Movement of Education through Art (Santos, 2006). These processes have been, since the last decades, largely developed in educational and therapeutic contexts helping people of all ages. Several authors refer the importance of artistic expression (in their different modalities) on special education and inclusive and multicultural education.

Also, Grytting (2000) reviewed several articles and concluded that education through art improves spatial skills, and kinaesthetic children promoting interpersonal and intrapersonal intelligence, giving children and adolescents the opportunity to express emotions and helping their social development. The school is an ideal place for young people to have a systematic contact with different art forms and its languages: visual arts, theatre, dance, music and literature. If we prepare teens to read images produced by artists, we will prepare them to read the images that surround them. This way the art of teaching breaks exclusion barriers, because the educational practice is not only attached to the talent but also to the trial capacity of each. We can provide incentives to students to risk drawing, represent, dancing, playing and writing as they are experiences and not a competition. Only this way, young people will recognise themselves as participants and builders of their own ways.

The choice to address this problem arises from some questions: which artistic expression that is chooses for, or by whom? All the modalities are appropriate for all? The choice of any expression leads to the same emotional result? Then what to choose?

Today, we witness a growing presence of young people from disadvantaged social groups, excluded due to lack of resources, risk behaviour; they have few symbolic references, no sense of belonging, values or rules. Some of them were victims of a territorial-geographic exclusion inhabiting peripheral housing estates. The street is a common space and the street itself has become a platform where artists can express and often convey their personal views, values and opinions as if it was a diary. This form of communication, inadvertently or not, has become part of our daily visual culture and arises through two different art forms: street art and graffiti.

Infused in the emergence of hip hop culture (in the $70 \mathrm{~s}$ and 80s), the graffiti which was initially seen as a form of vandalism, and a threat to society is currently transformed and changed into what is known as 'street art' (Lewishon, 2008). If at first the art of graffiti emphasised the proliferation of anonymity through the use of creativity, currently street art and graffiti art are closely related, being increasingly used as a means of mass communication and publicity. 
To the undiscerning eye, street artists and graffiti artists are easily associated with gangs (Gross \& Gross, 1993). However, these differ because while the gangs are interested for establishing territorial limitations, street artists and graffiti are more interested in developing a reputation through selfproliferation, winning street fame in relation to his art. Many street artists, graffiti artists and teens, male or female, use the writing graffiti as an experience on its own identity, working to develop a sense of 'I' and helping them from adolescence to adulthood (Othen-Price, 2006).

According to Hughes (2009), a study of graffiti art with adolescent students and their teachers reveals that for most of them it is an attractive and challenging art that enriches and stimulates critical thinking of students. This type of critical thinking encourages students to question the definition of art, expanding their own personal definition. According to this author, for educators to the secondary school level, a lesson in the art of street graffiti can bridge the gap between daily visual culture of life and the art world. For students of urban secondary school, street and graffiti, it is an inevitable part of your daily visual culture (Whitehead, 2004).

Now we think in the educational process of these young people and the challenges for its inclusion.

Inclusive Education, base that ensures an Inclusive Society, is based on valuing differences by reducing barriers to learning and promoting social cohesion, belonging, active participation in learning and school, the experience of positive interactions with peers and other members of the school community.

Being school a privileged space for the development of socialisation, cognitive abilities, emotional capabilities and communication skills, it is also the place where young teenagers spend most of their time and relate to their peers; so, and taking into account the definition of aggression of Ramirez (2001), the school is a favourite room for the existence of aggressive moments.

In fact, nowadays school, mainly in urban contexts, faces numerous children and adolescents who for several reasons have developed aggressive and challenging behaviours and high risk of dropping out school. The persistence over time of these behaviours is multifactor but probably also due to the fact that it is perceived as natural, and enrolled in a regular pattern of interaction and its consequences are sometimes undervalued (Leonardo, 2007).

Often aggression and challenging behaviours at school appears as a mechanism of defense and affirmation. Many of these children and adolescents at risk come from sociocultural or socio-economic minority groups; they are sometimes adolescents with a repeated course of academic failure. The school difficulties may create a situation of discouragement and failure, because the more diminished the young feel, the more susceptible to failure they are. Young people, who demonstrate learning difficulties, see themselves more negatively than those who have a satisfactory academic performance. It is then necessary to find strategies that encourage these young people to become interested in teaching activities, these strategies cannot limit their creativity and the way they express their feelings. The classroom should be a place where no student should feel diminished, should be a pleasant space that provides increased self-esteem and decreased frustration. Students with challenging behaviour are seen as a problem because they strongly disturb the conduct of school activities. Many times they are seen as students with special needs and initiates journeys of social maladjustment. To segregate these students, it is foreclosing equal access to social and curricular opportunities.

Inclusive school recognises and valorises differences, also in learning. This does not imply that we have to learn all according to different methodologies, as this would make the whole process of teaching/learning impossible to achieve. This means 'that the objectives and strategies are not innocuous: all are based on conceptions and learning models. So if we don't provide different approaches to the learning process, we will eventually create inequality for many students' (Rodrigues, 2006).

Schools of today have the responsibility to educate young people (with or without special educational needs) with social, academic and personal skills in an attractive manner and in a way that increases their motivation for learning.

Art, in its various expressions, has had the ability (always!) to bring together the interests of all, even of the most unsuitable. The same happens at school. However, the potential of artistic expression is not sufficiently used as a development facilitator in adolescents particularly at the level of the everyday teaching practices of the third cycle and secondary level.

This justifies the importance of this study where we attempt to adapt the artistic expression (through an approach to graffiti art) to students with challenging behaviours who come from an urban disadvantaged environment. For that we propose an intervention programme in class as a way of emotional expression and possibility of change social behaviours.

\section{Method}

The general goal of this research is to know if graffiti art can, through its application in the educational context, change challenging behaviours of students from schools in urban areas.

In this perspective, we established the follow objectives: verify if there are changes on behaviour with teachers, with colleagues and if there are specific changes in prosocial behaviours. 
To achieve these objectives, it was structured, implemented and evaluated an Intervention Programme with specific aims for a group of teenagers with challenging behaviours.

The behavioural changes were assessed during the implementation of the intervention programme in several directions: behaviours directed to the teacher; behaviours aimed at colleagues and changes in prosocial behaviours.

\section{The programme}

The programme was implemented in a ninth grade class covered by PIEF Programme (Integrated Programme for Education and Training). The class has nine students, four boys and five girls (chosen by teachers due to the characteristics of students).

It occurs in fourteen sessions (90 minutes each) during 2 months and a half.

This intervention programme have specific objectives: to promote in students, the development of affective and behavioural dimensions in the intra- and inter-individual relations (namely the reduction in aggressive behaviour, the promotion of empathy and pro-social attitudes, the respect for rules, a greater integration in the group of pairs, promoting motivation for school activities and reduce absenteeism).

The programme consists of:
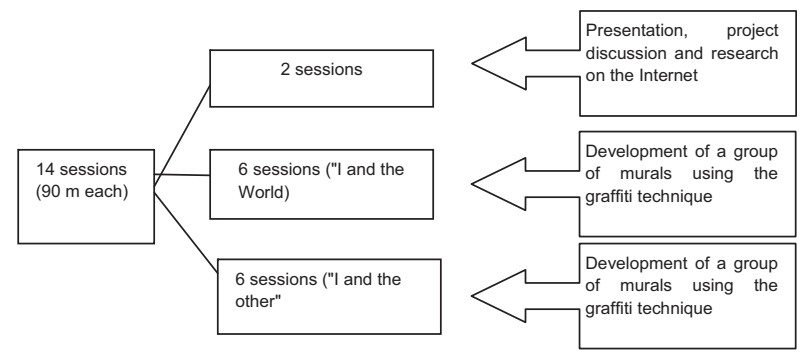

Students will be presented two themes 'I and the World' and 'I and the other' to the achievement of two murals. The topics have been chosen taking into account that it is intended to make students think their relationship with what surrounds them going from the general 'World' for the particular 'others'.

Throughout the implementation of the programme, the teacher made several brainstorming sessions to lead students to think about the issues and the information that they wanted for their murals, their ideas, feelings, emotions, anger and so on.

\section{Instruments and procedure}

The study is divided into three phases: before, during and after the intervention programme. Before the start of the programme, we request questionnaires to two class teachers with the aim of collecting data about each student. During the intervention programme, it was offered to students the possibility of the 'making of' the murals based on the two themes provided before: 'I and the world' and 'I and the other'. All the sessions were recorded by video. After the development of the programme, we analysed the video images made during the sessions.

Data collection were made in the school context, based primarily: (1) on direct observations of the class recorded in video; (2) on questionnaires carried out to two teachers of the class.

The instrument used to analyse behaviours on video images; it was a Categorical Behaviour Observation Grid, adapted from Oliveira (2001). Behaviour categories observed during each of the observations were, namely: directed behaviour to the activity (conversation, disturbs; stops, walks out of class; modifies the activity; is involved in the activity and demonstrates satisfaction), directed behaviours to Professor (obedience, refusal, rudeness, others), directed behaviours to colleagues (rudeness, dangerous acts, uncooperative, others), prosocial behaviour (smile, looks into the eyes while talking, communicating feelings verbally).

The process of observations focused on a constant number of students in one class. These observations were 36 in number, distributed in number of six per each of the six classes observed over time for a period of 2 months and a half, with uniformly distributed events.

For each student, it was observed in each class during three moments: at the beginning, middle and end of the class.

The analysis was done to each individual student in seven interspersed classes. A lifting behaviour grid of all students per class was made later. At the end, it was made a summary grid of the behaviour of all students in all the classes observed.

\section{Results and discussion}

The effect of implementing the intervention programme using the technique of graffiti on student behaviour in the classroom was observed. The statistical analysis is focused on two dimensions: the first one is the analysis of the impact of the programme on each category individually; the second is the analysis of the graffiti art impact on each group of categories. With these data, we intend also analyse the existence of behavioural changes along each class individually and verify if these behaviours are maintained or not at the same moments of the next classes (at the beginning, middle and end of class). That is, we intend to evaluate along the intervention programme if there were stable behavioural changes.

The results of first dimension point out to positive influence of graffiti programme on some behaviours of this 
group, particularly in the categories addressed to activity and to colleagues: conversation, disturbs, walks out of class, modifies the activity, cooperation, with reduction in negative behaviours. Although these behaviours have not been eradicated, a strong decrease is verified in the categories of behaviours addressed to colleagues (disturbs, uncooperative) and a significant decrease in some categories of behaviours addressed to activity (modifies the activity, walks out of class and others). It was interesting to note that the most positive results were given in the categories of behaviours related to the (proposed) activity (such 'involved in the activity'), and the categories related with behaviours to colleagues, which leads us to suggest that along each class, from start to the end, the environment could becoming more motivated and open to other. The behaviour directed to the teacher has suffered the least modification.

The results of the second dimension point out to a strong impact negatively correlated with negative behaviours directed to colleagues and also a significant impact negatively correlated with negative behaviours directed to the activity.

In the course of the intervention programme, it became clear that the interest of students for the activities related to art graffiti translating into a positive change in behaviour directed to colleagues and to the activity.

\section{Conclusions}

Although many in these categories do not lead to significant changes in behaviour, the fact that some challenging behaviour to colleagues and the activity have been positive changes; it demonstrates that something happened during the intervention programme through the graffiti art impacting the relationship of these students towards the development of prosocial behaviour.

Given the positive results achieved, and because we were involved in the intervention, we could say that through art graffiti, it was possible to verify the existence of an emotional release. Simultaneously was felt increased confidence of students in relation to the proposed activities allowing students experiencing situations of success and recovery of their personal and academic skills.

When presenting the project, we felt in students a kind of fear of what we asked them for. We found that it was not usual for those students speak or show what they had in their soul. In the beginning it was not easy, it was too difficult to get exteriorised feelings; it was necessary through relaxing sessions of brainstorming ideas trying to take them to reality. Explaining that no one would be reproached for their ideas, be they good or bad. The class would be a space for sharing opinions and ideas. When this moment arrived, it was like a liberation moment, the classroom became a relaxed place where everyone did what they knew best.
This work got us the pleasant feeling that the graffiti had the ability to win in the class because it is a form of expression closely linked to these students' experiences; using this technique, the students were given the ability to grow and at the same time were being aware of their capacities. It was immensely gratifying to see that everyone in the room was growing over time. Getting students that in the first wall refused to work in a group and on the second wall already accepted the evidence was more than enough proof that it was worth being there.

There are some aspects that limited this research. First the duration of the action, since the most effective interventions have a higher number of sessions and are more intensive and frequent. The school space also put some limitations to the development of this research: we worked in a classroom space which is not the most appropriate to the practice of graffiti. It was a normal classroom in which students had to work on an adapted wall trying to approach the reality, that is to paint a wall that everyone can see and through which one can truly convey a message.

As a little contribution to this discussion, the study shows that street art/graffiti experience can be an asset to the educational development and a possible teaching resource and cross-cutting theme to an inclusive education of the students with challenging behaviours contributing to a better inclusive school.

One of our suggestions for future is to link this school work (with also academic aims) to a community work, developing a true work between Inclusive Education and Social Inclusion.

\section{Conflicts of interest}

There is no conflict of interest.

\section{References}

Gross, D. \& Gross, T. (1993) Tagging: Changing Visual Patterns and Rhetorical Implications of a New Form of Graffiti, etc. A Review of General Semanties, 50 (3), pp. 251-264. Institute of General Semanties: Et Cetera.

Grytting, C. (2000) 'The benefits of art education.' Arts and Activities, 127, pp. 66.

Hughes, M. (2009) Street Art \& Graffiti Art: Developing an Understanding. Atalanta: Georgia State University Digital Archive @ GSU. 
Lewisohn, C. (2008) Street Art: The Graffiti Revolution. New York: Abrams.

Oliveira, M. (2001) A indisciplina em aula de Educação Fisca Doctoral Tesis. Porto: FCDEF - UP.

Othen-Price, L. (2006) 'Making their mark: a psychodynamic view of adolescent graffiti writing.' Psychodynamic Practice, 12 (1), pp. 5-17.

Ramirez, F.C. (2001) Condutas Agressivas na Idade Escolar. Amadora: McGraw-Hill.

Rodrigues, D. (2006) Inclusão Educação, Doze olhares sobre a Educação Inclusiva. São Paulo: Summus Editorial, 85-323-0078-2.
Rogers, N. (1997) The Creative Connection: Expressive Arts as Healing. California: Sience and Behavior Books.

Santos, G. D. (2006) Dançoterapia Integrativa - uma metodologia de intervenção em Comportamentos Agressivos, PhD Tesis, University of Évora.

Wasserman, G., Keenan, K., Tremblay, R., Coie, Y. and Locber, R. (2004) Fatores de risco e fatores de proteção da delinqüência infentil, Infância e Juventude, 3; pp. 51-86.

Whitehead, J. (2004) 'Graffiti: the use of the familiar.' Art Education, 57 (6), pp. 25-33. 